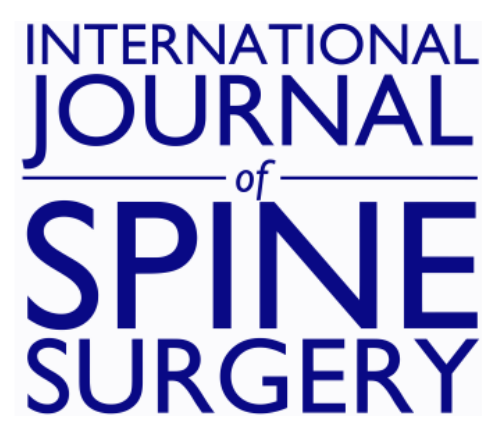

\title{
Biomechanics of Cervical Disc Arthroplasty--A Review of Concepts and Current Technology
}

Avinash G. Patwardhan and Robert M. Havey

Int J Spine Surg 2020, 14 (s2) S14-S28

doi: https://doi.org/10.14444/7087

http://ijssurgery.com/content/14/s2/S14

This information is current as of April 26, 2023.

Email Alerts Receive free email-alerts when new articles cite this article. Sign up at:

http://ijssurgery.com/alerts

The International Journal of Spine Surgery

2397 Waterbury Circle, Suite 1,

Aurora, IL 60504, Phone: +1-630-375-1432 


\title{
Biomechanics of Cervical Disc Arthroplasty-A Review of Concepts and Current Technology
}

\author{
AVINASH G. PATWARDHAN, PHD, ${ }^{1,2}$ ROBERT M. HAVEY, $\mathrm{MS}^{1}$ \\ ${ }^{I}$ Musculoskeletal Biomechanics Laboratory, Edward Hines, Jr. VA Hospital, Hines, Illinois, ${ }^{2}$ Department of Orthopaedic Surgery and Rehabilitation, Loyola \\ University Medical Center, Maywood, Illinois
}

\begin{abstract}
Activities of daily living require the subaxial cervical spine (C2-C7) to have substantial mobility. Cervical degenerative changes can cause abnormal motions and altered load distribution, leading to pain and limiting the ability of individuals to perform activities of daily living. Anterior cervical discectomy and fusion (ACDF) has been widely used to treat symptomatic cervical spondylosis. Clinical studies have shown cervical disc arthroplasty (CDA) to be a viable alternative to ACDF for the treatment of radiculopathy and myelopathy. The benefits of CDA are based on the premise that preservation of physiologic motions and load-sharing at the treated level would lead to longevity of the index-level facet joints and mitigate the risk of adjacent segment degeneration.

This review article classifies cervical disc prostheses according to their kinematic degrees of freedom and device constraints. Discussion on how these design features may affect cervical motion after implantation will provide the reader with valuable information on how disc prostheses may function clinically.

The ability of a disc prosthesis to work in concert with remaining bony and soft tissue structures to restore physiologic motion and load-sharing is a function of the following design features and surgical factors:

1. Kinematic degrees of freedom-Prostheses that allow translation independent of rotation allow, in theory, the spinal anatomy to dictate segmental motion after CDA potentially restoring physiologic motion and load-sharing. A 6-degrees-of-freedom disc prosthesis may be best equipped to achieve the intended function of CDA.

2. Built-in stiffness-A disc prosthesis with built-in resistance to angular and translational motion may have an advantage in restoring stability to a hypermobile segment without eliminating motion.

3. Surgical factors related to prosthesis implantation may influence cervical segments after CDA. These factors include the amount of disc space distraction caused by the prosthesis, prosthesis placement in the sagittal and coronal planes, and integrity of the soft tissue envelope.
\end{abstract}

Special Issue-Biomechanics

Keywords: cervical spine, cervical disc arthroplasty, total disc replacement, biomechanics

\section{INTRODUCTION}

Activities of daily living require the subaxial cervical spine (C2-C7) to have substantial mobility in flexion-extension, lateral bending, and axial rotation. ${ }^{1-3}$ These segments also demonstrate a characteristic coupling between lateral bending and axial rotation, dictated by the orientation of the articular facet surfaces and the uncinate processes. ${ }^{4-12}$ Degenerative changes in the cervical spine can cause abnormal motions and altered load distribution within the disc, leading to pain and limiting the ability of individuals to perform activities of daily living.

Historically, anterior cervical discectomy and fusion (ACDF) has been widely used to treat symptomatic cervical spondylosis. ${ }^{13-16}$ Clinical studies have suggested that cervical fusion predisposes the remaining mobile segments to accelerated degeneration. ${ }^{17-21}$ Biomechanical studies have reported increased motion and stresses in adjacent segments after fusion, which were thought to accelerate the degeneration. ${ }^{22-26}$ Several clinical studies have shown cervical disc arthroplasty (CDA) to be a viable alternative to ACDF for the treatment of radiculopathy and myelopathy. ${ }^{19,27-40}$ The proposed advantages of disc arthroplasty are based on the premise that preservation of physiologic motions and load-sharing at the treated level leads to longevity of the facet joints at the index level and mitigates the risk of adjacent segment degeneration. 


\section{BIOMECHANICAL FUNCTIONAL GOAL OF CDA}

The goal of CDA is to restore normal biomechanical function to the diseased cervical spine segment, thereby allowing it to support the physiologic loads and motions of daily activities without pain. Therefore, the disc prosthesis must function in conjunction with the remaining soft tissue envelope (annulus, ligaments) and facet joints to allow restoration of physiologic quantity and quality of motion. The ability of disc arthroplasty to restore physiologic range of motion (ROM) and quality of motion depends on the design of the prosthesis and surgical factors associated with implantation of the prosthesis in the disc space. In the following, we expand on these concepts using data from the literature, where available, and on the basis of our experience in assessing the biomechanical function of different artificial disc prostheses.

\section{CLASSIFICATION OF CERVICAL DISC PROSTHESES DESIGNS}

Artificial cervical disc prostheses have been classified over the years using different criteria. Sears et $\mathrm{al}^{41}$ used kinematic degrees of freedom (DOF) and constraints to classify various cervical and lumbar disc prostheses. Büttner-Janz ${ }^{42}$ classified various prostheses on the basis of the number of articulating components that form joints (bearings) to produce motion within the prosthesis. The discussion in the literature regarding the classification of artificial disc prostheses is complicated by the ambiguity surrounding the use of terms such as constrained and semiconstrained. The meaning of the term constraint as applied to the biomechanics of artificial disc prostheses was first discussed by Huang et $\mathrm{al}^{43}$ for lumbar disc prostheses and later expounded by Sears and colleagues ${ }^{41}$ and used to classify cervical and lumbar disc prostheses. The term constraint refers to the limit on the number of DOF an object has during its motion in threedimensional (3-D) space. An object with zero constraints on its movement is said to have 6 DOF in 3-D space, which is to say it can rotate independently about 3 orthogonal axes and translate independently along these 3 axes. All 6 components of motion are independently possible; for example, translational motion of the object can occur without the need for rotation.
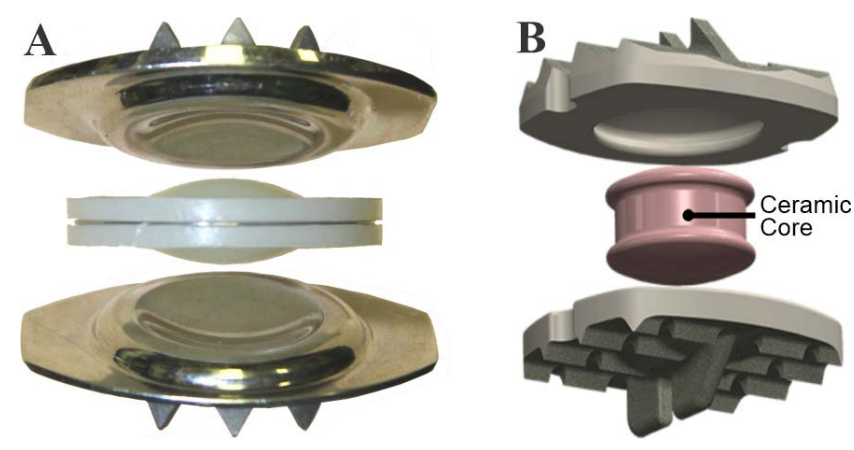

Figure 1. A disc prosthesis with 3 components including a biconvex mobile core that articulate in 2 spherical bearings (ball-and-socket joints). (A) The Charité lumbar disc. (B) The Simplify cervical disc prosthesis (Source: Simplify Medical, Inc).

\section{Three-Component Cervical Disc Prostheses}

The kinematic DOF of a disc prosthesis are determined by the nature of articulation of the bearing surfaces of the prosthesis. A disc prosthesis with 3 components can have 2 articulating bearings (joints; Figure 1). For example, a prosthesis with an incompressible, biconvex core will have 2 DOF in the sagittal and coronal planes because the mobile core can allow translational motion between the 2 vertebrae of the implanted segment without the need for angular motion between the 2 vertebrae.

The kinematic DOF of prosthesis motion in the sagittal (or coronal) plane can be calculated using the following equation, which was originally proposed for the mobility analysis of planar kinematic chains ${ }^{44}$ :

$$
\mathrm{DOF}=3(N-1)-2 P_{1}-P_{2},
$$

where $N=$ number of components (links) of a kinematic chain, $P_{1}=$ number of joints in the kinematic chain having $1 \mathrm{DOF}$, and $P_{2}=$ number of joints in the kinematic chain having 2 DOF.

In the example of a prosthesis with an incompressible biconvex mobile core, the kinematic chain has 3 components $(\mathrm{N}=3)$ and 2 joints, each of which allows 1 DOF; namely, angular motion in the sagittal (or coronal) plane $\left(\mathrm{P}_{1}=2\right)$. Neither of the 2 bearings allow 2 DOF (2 independent motion components); therefore, $\mathrm{P}_{2}=0$. Substituting these values in (1) we obtain $\mathrm{DOF}=3(3-1)-2(2)-0=2$ (ie, 2 DOF in the sagittal and 2 DOF in the coronal planes).

Note that the above equation for calculating kinematic DOF of a prosthesis is valid for the motion of the prosthesis when viewed in a plane and not in 3-D. 

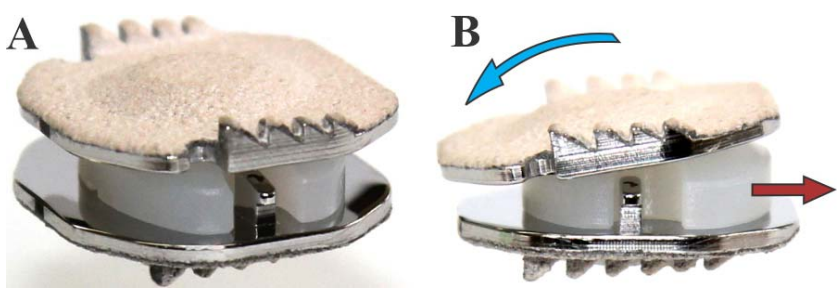

Figure 2. Another example of a prosthesis with 3 articulating components with 2 bearings is the Mobi-C cervical artificial disc. The bearing (joint) formed by the mobile core with the superior prosthetic endplate is spherical. The core forms a planar bearing with the inferior prosthetic endplate. Endplate angular motion (blue arrow) will result in a corresponding translation of the core (red arrow).

In the axial plane the prosthesis has 1 additional DOF that is unaccounted for in the sagittal- or coronal-plane motions; namely, axial rotation. Thus, a 3-component prosthesis with a biconvex mobile core will allow 3 independent angular motions (flexion-extension, lateral bending, and axial rotation), along with 2 independent translations (along anterior-posterior and lateral directions), for a total of 5 DOF. The only missing DOF is the ability to compress along the superior-inferior axis of the disc. Some examples of this prosthesis design include the Charite lumbar disc, the Kineflex $\mid C$, or the more recent Simplify cervical disc.

Another example of a prosthesis with 3 articulating components with 2 bearings is the Mobi-C cervical artificial disc (Figure 2). The bearing (joint) formed by the mobile core with the superior prosthetic endplate is spherical, which allows 3 independent angular motions. The core forms a planar bearing with the inferior prosthetic endplate, which allows translational motions (up to $1.25 \mathrm{~mm}$ ) in the sagittal and coronal planes.

Thus, after substituting $\mathrm{N}=3, \mathrm{P}_{1}=2, \mathrm{P}_{2}=0$ in (1), it is once again found that the motion of the Mobi-C prosthesis when viewed in the sagittal (or coronal or axial) plane will allow 2 DOF each. The Mobi-C prosthesis will allow 3 independent angular motions and independent translational motions in the anterior-posterior and lateral directions, yielding a total of 5 DOF in 3-D space. The only missing DOF is the ability to compress along the superiorinferior axis of the disc.

The Secure-C disc prosthesis has a mobile core that forms a spherical (ball-and-socket) bearing with the superior prosthetic endplate and a cylindrical bearing with the inferior prosthetic endplate with the long axis of the cylinder aligned in the coronal plane (Figure 3).

The cylindrical and spherical joints both allow flexion-extension motions and therefore the upper
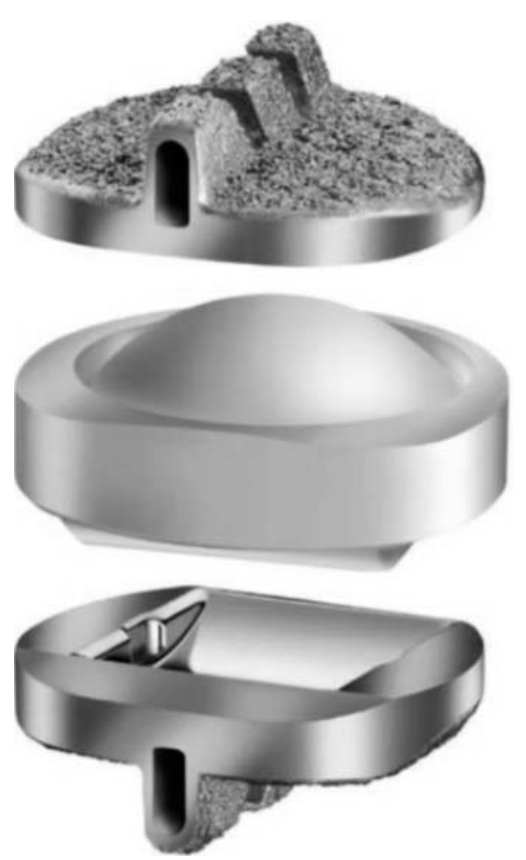

Figure 3. The Secure- $C$ disc prosthesis has a mobile core that forms a spherical (ball-and-socket) bearing with the superior prosthetic endplate and a cylindrical bearing with the inferior prosthetic endplate with the long axis of the cylinder aligned in the coronal plane (Source: Globus Medical).

vertebra can translate in the anterior-posterior direction without the need to undergo flexionextension angular motion. As a result, in the sagittal plane the prosthesis allows motion with 2 DOF. In the coronal plane, the angular motion in lateral bending is only allowed at the superior spherical joint. The inferior cylindrical joint is nonfunctional in the coronal plane; that is, the prosthesis functions as a 2-component prosthesis in this plane with $\mathrm{N}=$ $2, \mathrm{P}_{1}=1$, giving a $\mathrm{DOF}=1$. The Secure-C prosthesis allows 3 independent angular motions (flexionextension, lateral bending, and axial rotation) and 1 independent translation along the anterior-posterior direction, yielding a total of 4 DOF. No translation motion is allowed along the superiorinferior direction or in the lateral direction in the coronal plane.

\section{Two-Component Cervical Disc Prostheses}

Artificial cervical disc prostheses with 2 functional components that articulate to produce motion in the prosthesis can have different kinematic DOF depending on the type of bearing (joint). A prosthesis with 2 articulating components with 1 spherical bearing (ball-and-socket joint) has $3 \mathrm{DOF}$ because it can only allow 3 independent angular motions; namely, flexion-extension, lateral bending, and axial rotation. No translational motion between 

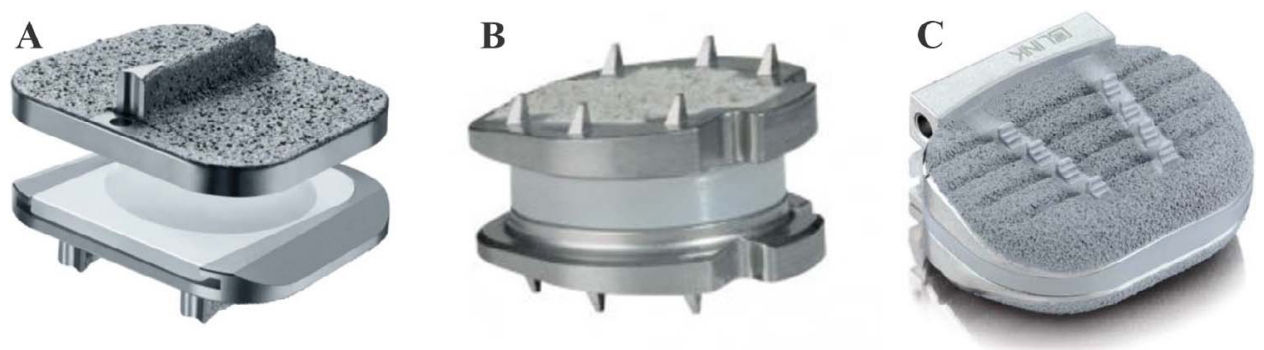

Figure 4. Prostheses with 2 components that articulate to form a spherical (ball-and-socket) joint. (A) ProDisc-C (Source: Centinel Spine). (B) Discover (Source: DePuy Synthes Spine). (C) PCM (Source: NuVasive).

the 2 components is possible if the conformal bearing surfaces remain fully in contact during the arc of motion. Some examples of this class of cervical disc prostheses include the ProDisc-C, DePuy Discover, and Porous Coated Motion (PCM) discs (Figure 4).

Other examples of joints that prostheses with 2 articulating components form include a saddle joint, a ball-and-trough joint, and 3 noncongruent balland-socket joints (Figure 5). A saddle joint allows independent angular motions in 2 orthogonal planes; for example, flexion-extension and lateral bending. Therefore, a prosthesis with an articulating saddle joint will have 2 DOF. An example of this design is the Cervicore disc (Figure 5A), which is no longer in clinical use. ${ }^{45} \mathrm{~A}$ ball-and-trough articulation, such as in the Prestige disc (Figure 5B), allows 3 independent angular motions (flexion-extension, lateral bending, and axial rotation) and translation independent of flexion-extension angular motion in the sagittal plane. ${ }^{39}$ Therefore, a prosthesis with a ball-and-trough articulation will have 4 DOF.

A recent addition to the category of 2-component prostheses is a design with a 3-lobe articulation in which the mating surfaces are noncongruent (Triadyme-C; Figure 5C). The radii of the lobes are smaller than the corresponding pockets. Because of this design, load transfer from the superior lobes to the inferior pockets occurs over a small surface area, resulting in very high contact stresses. Industrial polycrystalline diamond, specially formulated and processed for biocompatibility, is used to resist the high contact stresses. This prosthesis allows 3 primary rotations, coupled with anterior-posterior and medial-lateral translations. ${ }^{46}$ The device is noncompressible with 3 DOF.

\section{Nonarticulating Cervical Disc Prostheses}

The last category of discs consists of nonarticulating discs with compliant cores; for example, a polycarbonate polyurethane core that allows compression or shortening of the disc prosthesis height. This component of motion, which was missing in the incompressible designs, allows the disc to have all 6 DOF. Some examples of this design include the Bryan, the M6-C, the Rhine, and the ESP discs (Figure 6).

In addition to the kinematic DOF, an additional characteristic for each cervical disc prosthesis (namely, the ability of the prosthesis to offer a built-in or inherent resistance to angular and translational motions) is an important design feature that affects its ability to restore physiologic motion as well as stability, both of which are the functional goals of a cervical disc prosthesis.
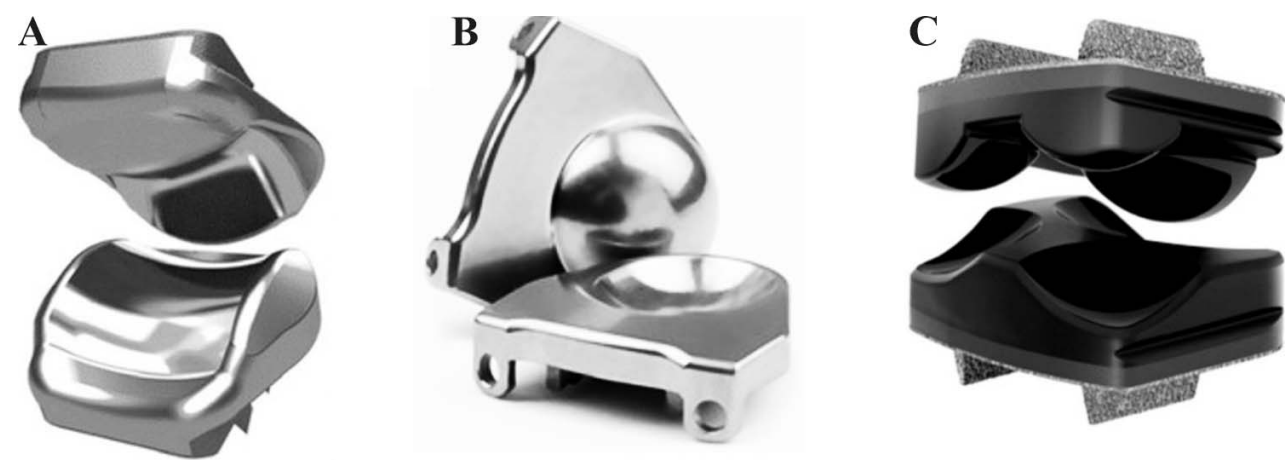

Figure 5. Prostheses with 2 components that articulate to form (A) a saddle joint (Source: Stryker Spine), (B) a ball-in-trough joint (Source: Medtronic), and (C) 3 noncongruent ball-and-socket joints (Source: Dymicron, Inc). 
A
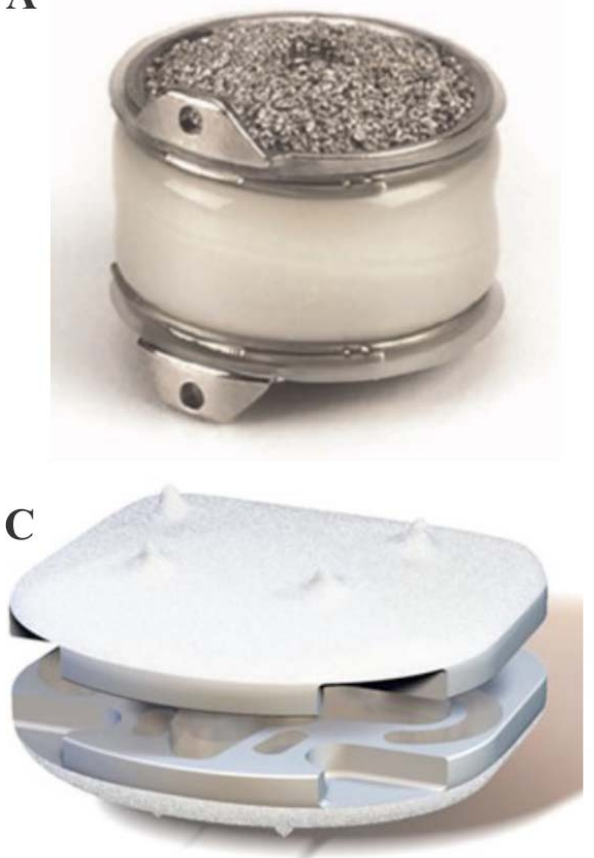

B
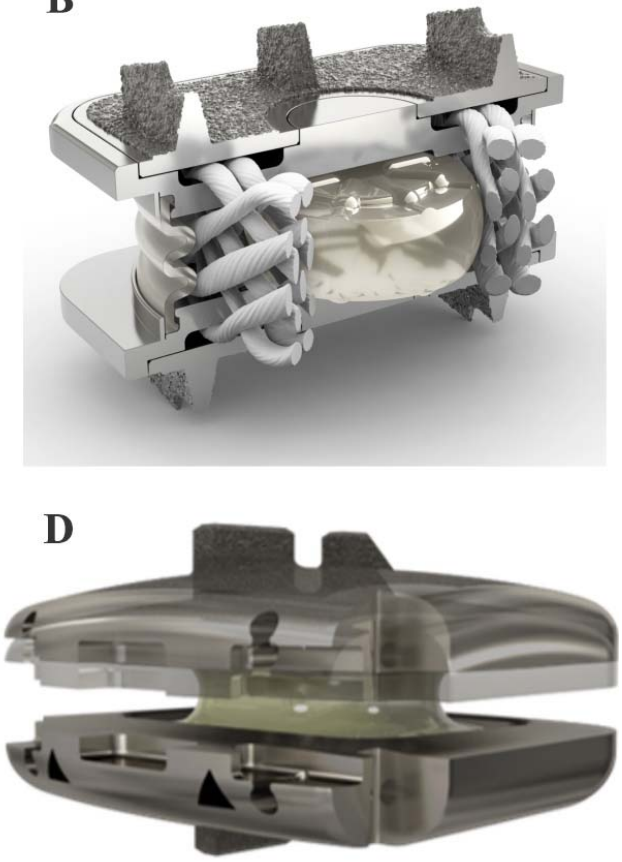

Figure 6. A class of nonarticulating discs with compressible cores. (A) Bryan disc (Source: Medtronic), (B) M6-C disc (Source: Orthofix Spine), (C) CP-ESP disc (Source: FH Orthopedics Inc.), and (D) Rhine disc (Source: Stryker Spine).

The prostheses with compliant cores offer some amount of inherent resistance (stiffness) to angular and translational motions. The amount of intrinsic stiffness due to the compliant core varies depending on the dimensions of the core and its fixation to the prosthetic endplates. Of the discs with a compliant core, the M6-C disc incorporates an additional feature; namely, an artificial annulus made of polyethylene fibers woven through holes in the 2 inner metal endplates of the disc. The fiber annulus provides added bending stiffness to the disc, a feature that can be important for restoring bending stiffness to a hypermobile segment. Sears and colleagues $^{41}$ suggested that when prostheses offer intrinsic resistance (stiffness) against bending or translational motions they should be regarded as being restrained. A restrained prosthesis should not be confused with one that has built-in physical stops for limiting translational or angular motions allowed by the prosthesis.

\section{KINEMATICS OF HEALTHY CERVICAL SPINE SEGMENTS}

\section{Quantity of Motion (ROM)}

Several in vivo studies have measured segmental motions of the subaxial (C2-C7) cervical spine in healthy asymptomatic human subjects. The average
$\mathrm{ROM}$ in flexion-extension at $\mathrm{C} 5-\mathrm{C} 6$ was $15.6^{\circ} \pm 4.9^{\circ}$ according to a study ${ }^{2}$ of 50 healthy subjects. The average 1-sided lateral bending motion at C5-C6 was $4.3^{\circ} \pm 1.4^{\circ}$ in 12 subjects, and the average 1 -sided axial rotation motion at $\mathrm{C} 5-\mathrm{C} 6$ was $5.4^{\circ} \pm 4.3^{\circ}$ in 20 subjects. $^{1,3}$ With the primary motion in right rotation there is coupled motion in right lateral bending (Figure 7). Similarly, with the primary motion in right lateral bending there is coupled motion in right rotation. This has been measured in healthy human subjects and cadaveric specimens. ${ }^{4-12}$

\section{Center of Rotation and Axis of Rotation}

Movement of a cervical spine segment, also referred to as a functional spinal unit (FSU) (consisting of 2 vertebrae, intervertebral disc, facet joints, uncovertebral joints, and ligaments), involves both angular and translational motions of one vertebra relative to the other. For example, in the C5-C6 segment, flexion of the C5 vertebra is accompanied with some translational motion relative to C6. The second (ie, displaced) position of the C5 vertebra resulting from the combined angular and translational motion from its starting position can be exactly reproduced by a pure angular motion of $\mathrm{C} 5$ about a point denoted as the center of rotation (COR) of $\mathrm{C} 5$ relative to $\mathrm{C} 6$. The amount of anterior translation of $\mathrm{C} 5$ for every degree of angular motion 

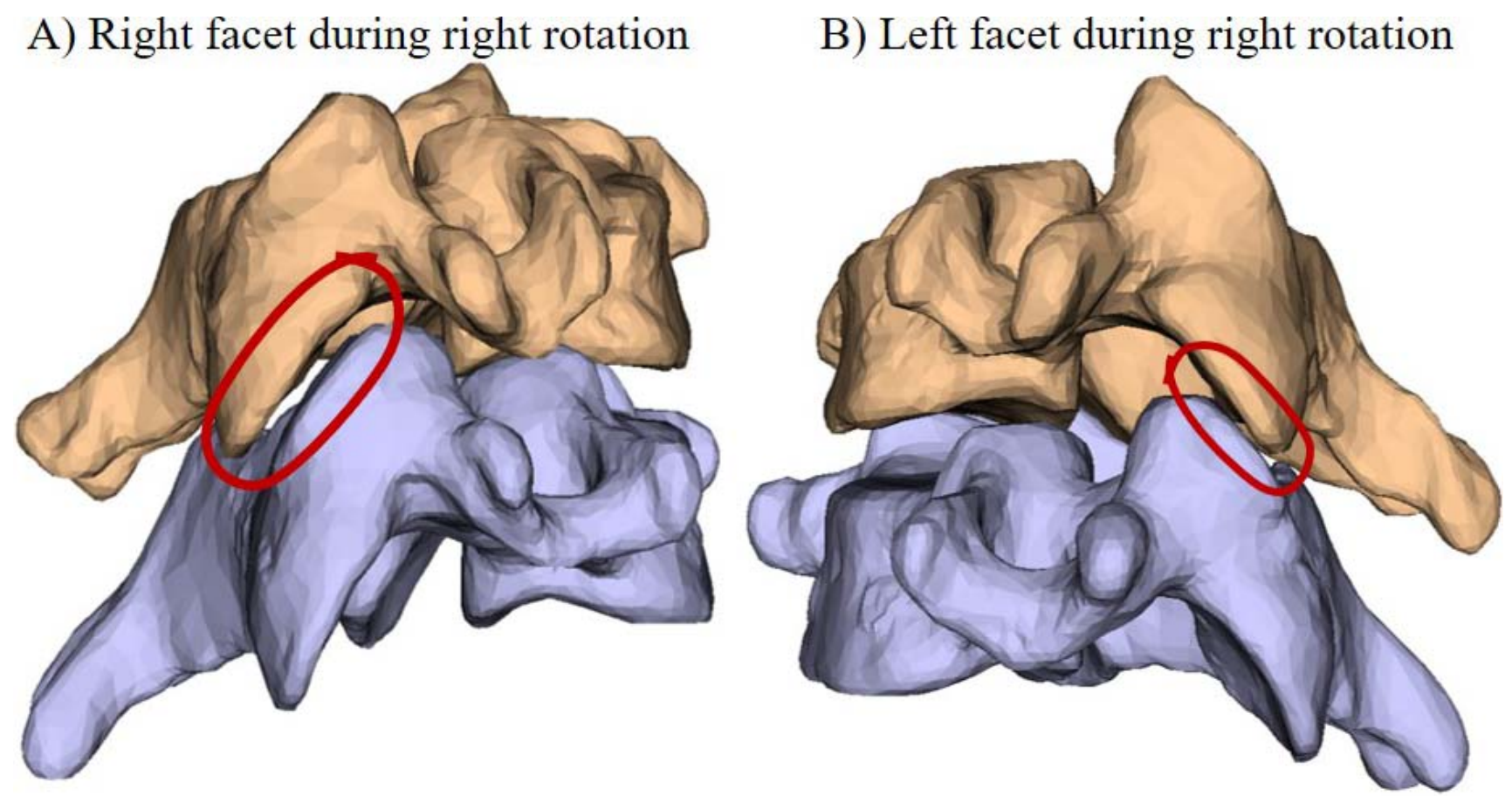

\section{C) Posterior view of right rotation}

\section{D) Posterior view of left rotation}
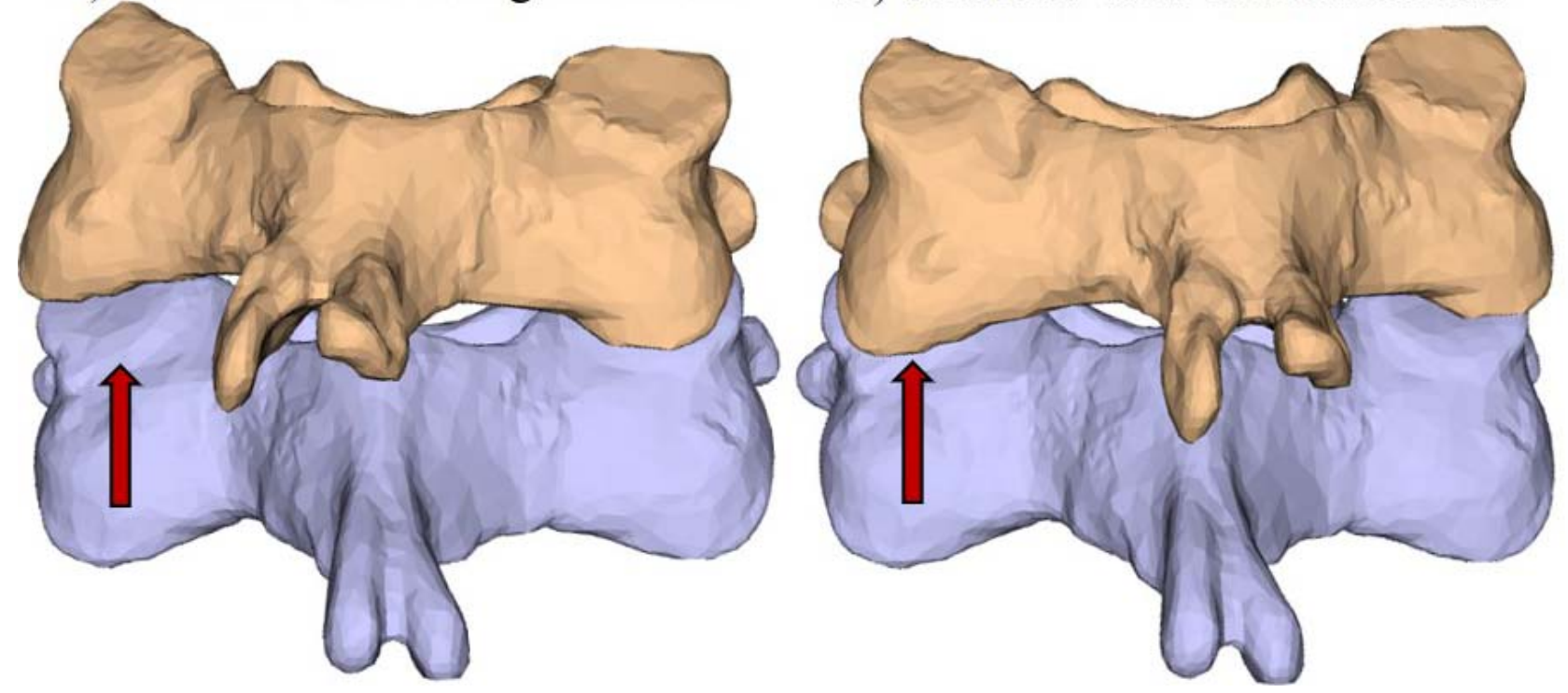

Figure 7. Axial rotation range of motion test of C5-C6. (A) View of right facet showing full overlap during right rotation, (B) left facet showing minimal facet overlap during right rotation, and (C) right rotation showing coupled right lateral bending. Transparent C5 body shows decreased facet overlap on left (D) left rotation showing coupled left lateral bending. Note increased facet overlap on left.

determines the location of this COR relative to the C5 vertebra. A unique COR location can be found for any 2 positions of a moving vertebra of a motion segment. For example, it is a common practice to calculate the average COR location during the extension-to-flexion motion of a spinal segment on the basis of the 2 x-rays taken of a patient in full extension and full flexion. Bogduk and Mercer $^{7}$ and Hipp and Wharton ${ }^{12}$ measured the average COR locations of human cervical spine segments by analyzing two x-rays taken in extension and flexion positions in healthy human subjects. The location of the average flexion-extension COR varied along the length of the spine; it was located more caudally in the upper cervical segments (C3-C4 and C4-C5) and moved closer to the lower endplate of the intervertebral disc for the lower cervical segments (C5-C6 and $\mathrm{C} 6-\mathrm{C} 7)$. Thus, the vertebrae in the upper 

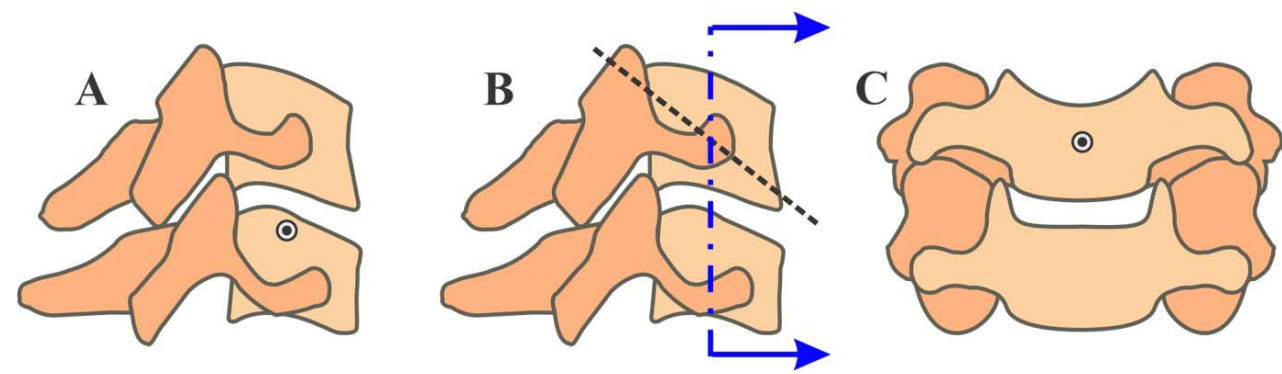

Figure 8. Axes of rotation in a healthy C5-C6 segment: (A) flexion-extension COR, (B) lateral bending axis of rotation shown in sagittal projection, and (C) intersection of lateral bending axis with the midcoronal plane. COR, center of rotation.

cervical segments experienced greater translational motion than the lower cervical segments for the same degree of flexion motion at each segment. However, it is possible that rotation of the moving vertebrae about this average COR may not fully capture the vertebral motion path between the 2 endpoints of motion. This is because the instantaneous center of rotation (ICR) does not remain stationary during the arc of motion; the movement of the ICR depends on the amount of translation associated with flexion, which, in turn, depends on the segment level and the health of the motion segment.

In three dimensions, the angular motion of a vertebra can be described as a rotation about an axis; namely, the axis of rotation. The orientation and location of the axis of rotation in relation to the anatomical planes depend on the coupling between flexion-extension, lateral bending, and axial rotation motion components. If one considers motion in the sagittal plane as a pure flexion-extension angular motion, then the flexion-extension COR is equivalent to the intersection of the flexion-extension axis of rotation with the midsagittal plane. Because of the characteristic coupling of right lateral bending and right axial rotation motions, the axis of rotation in this mode of motion is oriented from posteriorsuperior to anterior-inferior direction and the axis intersects the superior vertebra just above the superior endplate of the intervertebral disc in the midsagittal plane (Figure 8). Analogous to the ICR is the instantaneous axis of rotation (IAR). The IAR path traces a surface in 3-D space as the segment undergoes 3-D motion between 2 extreme positions; for example, from extension-right lateral bendingright rotation to flexion-left lateral bending-left rotation. The ICR is the projection of the IAR onto a plane (3-D to 2-D projection).

\section{Kinematic Signature}

The kinematic signature (moment versus angular motion curve) of a healthy cervical segment is sigmoidal (Figure 9) and is the net result of progressive resistance offered by the intervertebral disc and ligaments as the segment undergoes angular motion in response to gradually increasing applied moment. It is characterized by a region of high flexibility around the neutral posture, which is capped at both ends by a region of high stiffness due in part to nonlinearly increasing resistance of the disc, tightened ligaments, and load-sharing by the facets and facet capsules. ${ }^{47}$ One of the clinically relevant measures of quality of motion can be derived from the response of a spinal segment in this region of high flexibility (laxity) around the neutral posture of the spine (see Figure 9).

Neutral zone, expressed in degrees and calculated as the difference in the segmental angle between the loading and unloading curves at $0 \mathrm{Nm}$ bending moment, has been used in the literature ${ }^{48}$ to quantify the laxity around the neutral posture. However, calculation of the neutral zone based on the $0 \mathrm{Nm}$ crossing points could lead to erroneous results due to asymmetries in the load-displacement curves induced by experimental artifacts, prosthesis kinematics, or postoperative changes in posture. Therefore, we prefer to use the stiffness of the motion segment in its high-flexibility zone as a measure of the laxity around the neutral posture. Panjabi $^{49}$ postulated that an increased laxity, as demonstrated by a substantially decreased stiffness around the neutral posture of the spine, would put increased demand on the spinal musculature to provide the stability needed during activities of daily living. Increased spinal muscle forces would, in turn, increase stresses in the spinal components and might contribute to pain. 

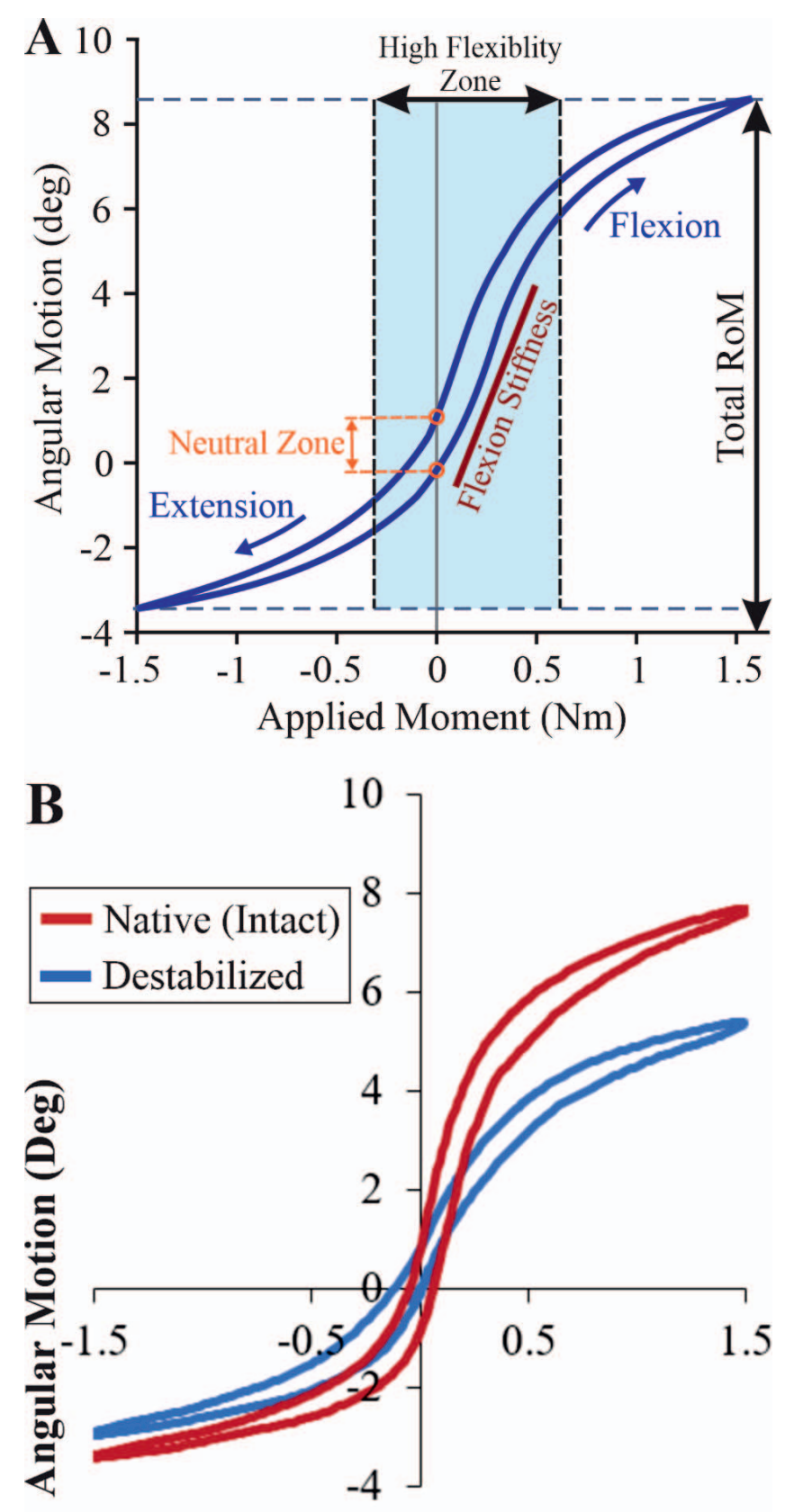

Applied Moment (Nm)

Figure 9. (A) Kinematic signature of a cervical spine segment in flexionextension. (B) Effect of decompressive surgery on the kinematic signature showing increased laxity (decreased stiffness) around the neutral posture, resulting in larger range of motion.

\section{PROSTHESIS DESIGN AND MOTION AFTER CDA}

The goal of CDA is to restore physiologic mechanics at the index segment. The prosthesis can accomplish this goal by restoring physiologic quantity (ie, ROM) and quality of motion.

\section{Quantity and Quality of Motion}

We compared the ROM of cervical segments implanted with different designs of disc prostheses. ${ }^{50}$ A total of 60 disc prostheses of 3 design types were implanted: fixed-core discs with a single spherical bearing, mobile-core discs with 2 spherical bearings, and nonarticulating, compressible-core discs. An anterior window was made in the annulus just wide enough to accommodate the prosthesis width. The anterior-lateral corners of the annulus fibrosus were left intact to provide stability during extension after prosthesis implantation. During implantation the posterior longitudinal ligament (PLL) was resected while the uncinate processes were left intact. All disc prostheses were implanted at either $\mathrm{C} 5-\mathrm{C} 6$ or $\mathrm{C} 6-\mathrm{C} 7$ with each prosthesis centered in the frontal plane and slightly posterior to the midline of the disc space in the sagittal plane.

All disc prostheses restored the ROM in flexionextension to within the physiologic range reported in the literature. We observed that disc arthroplasty significantly decreased the range of primary motions in lateral bending and axial rotation as well as the coupled lateral bending observed during primary axial rotation moment loading. This was true for fixed-core discs with a single spherical bearing, mobile-core discs with 2 spherical bearings, and compressible-core discs. The decrease in lateral bending motion and altered motion coupling after total disc replacement has been reported in previous biomechanical studies. ${ }^{51,52}$ These authors noted a decrease in total lateral bending of approximately $37 \%$ and a decrease in axial rotation of approximately $27 \%$ when loaded to $\pm 1 \mathrm{Nm}$ without preload. Snyder et $\mathrm{al}^{53}$ reported that total disc replacement using an artificial disc with a single spherical bearing design resulted in a $42 \%$ decrease in the lateral bending motion at the implanted segment $(P=.07)$. Finn et $\mathrm{al}^{45}$ reported that reconstruction of the $\mathrm{C} 4-\mathrm{C} 5$ segment with a bisaddle-shaped cervical disc prosthesis resulted in a $40 \%$ decrease in lateral bending and a $26 \%$ decrease in axial rotation. A recent study by Guyer et $\mathrm{al}^{54}$ reported similar ROM results for the Rhine disc (6 DOF elastic-core design): In flexion-extension, ROM was restored to physiologic values; whereas, in lateral bending and axial rotation the ROM was reduced postarthroplasty by $40 \%$ to $60 \%$.

The axes of rotation in flexion-extension, lateral bending, and axial rotation of the fixed-core, single spherical bearing (ball-and-socket joint) prostheses 

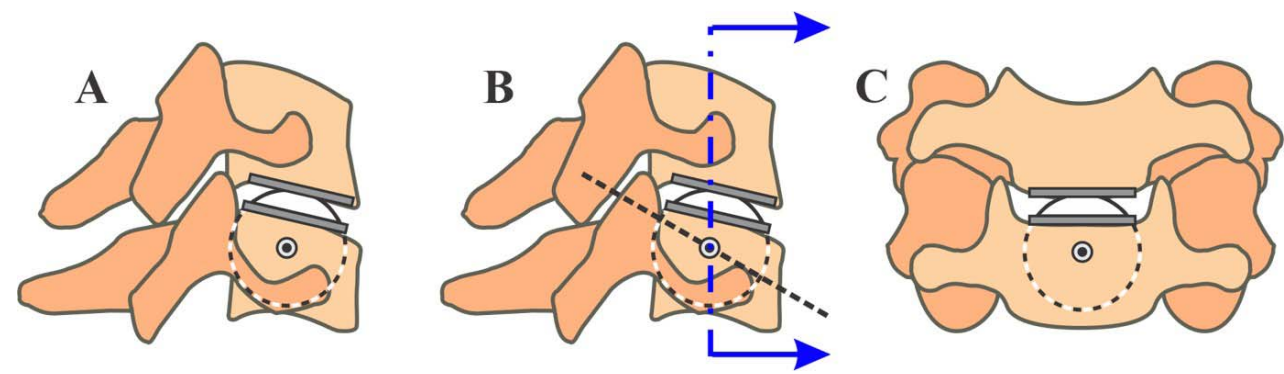

Figure 10. Axes of rotation in a reconstructed C5-C6 segment implanted with a single spherical bearing prosthesis: (A) flexion extension COR, (B) lateral bending axis of rotation shown in sagittal projection, and $(\mathrm{C})$ intersection of lateral bending axis with the mid-coronal plane. COR, center of rotation.

passes through the center of curvature of the spherical bearing, which is located caudally in relation to the disc space (Figure 10).

In a ball-and-socket articulation, the surface of the ball forms a portion of a sphere. Typically, the socket is implanted in the superior vertebra and the ball in the inferior vertebra of the segment. The center of the sphere would be the center of rotation for an arc of motion during which the bearing surfaces of the ball and socket remain fully in contact. The radius of the ball dictates the ratio of apparent translation experienced by the superior vertebra for every degree of angular motion. The "ball" in the PCM prosthesis has a much larger radius of curvature than other ball-and-socket-type prostheses and leads to greater apparent translation of the superior vertebra over the inferior. ${ }^{41}$ The location of the ball relative to the disc space will influence the center of rotation of the implanted segment, which will have an influence on the segmental motion and stresses experienced by the soft tissues and facet joints.

A ball-and-trough articulation such as in the Prestige prosthesis uses a spherical ball implanted in the superior vertebra and the trough or elongated socket in the inferior vertebra. In this design the ball can translate and rotate within the trough. Because of its ability to translate, the axis of rotation is not necessarily fixed as in ball-and-socket designs. This translation can hypothetically function to normalize the forces on the facet joints, but biomechanics of translating devices show decreased stiffness in the neutral posture that may be interpreted as instability by the body. This instability may result in increased muscle forces to control the instability as discussed in the "Kinematic Signature" section.

The axis of rotation in flexion-extension of the 6 DOF disc is also located in the disc prosthesis itself or slightly caudal to it. In lateral bending the axis of rotation of the native segment is in the cranial vertebra; whereas, the axis of rotation of the single spherical bearing prostheses, inherent to their design, is located well caudal to the location of the native axis. Therefore, this mismatch of lateral bending axes of rotation may contribute to limiting postarthroplasty motion in lateral bending. Whereas the 6-DOF compressible-core disc, in theory, has the potential to adapt to the lateral bending axis of rotation of the native segment, the observed decrease in lateral bending motion of the implanted segment suggested an apparent mismatch between the native and prosthesis axes of rotation. This may have to do with the inability of the prosthesis to accommodate the additional translation required to rotate about a more cranial axis of rotation due to the prosthesis stiffness in that mode of motion.

In axial rotation the native axis of rotation is more inclined in the superior-inferior direction compared with the lateral bending axis and passes through the disc space. Thus, the mismatch between the axial rotation axes of the native disc and the prostheses are not as great as in lateral bending. This is reflected in a smaller decrease in overall axial rotation motion than in lateral bending motion after disc arthroplasty.

The mobile-core design with 2 spherical bearings has the potential, in theory, to match the native axes of rotation in all 3 modes. The spherical bearing between the core and the upper endplate would allow matching of the axis of rotation in flexionextension, whereas the spherical bearing between the core and the lower endplate would give an axis in lateral bending that is in the cranial vertebra, similar to the location of the lateral bending axis in the native segment. Yet, results of recent in vitro experiments showed the mobile-core disc also decreased the lateral bending ROM at the implanted segment. This suggests the motions in flexionextension and lateral bending preferentially occurred at the superior bearing between the core 


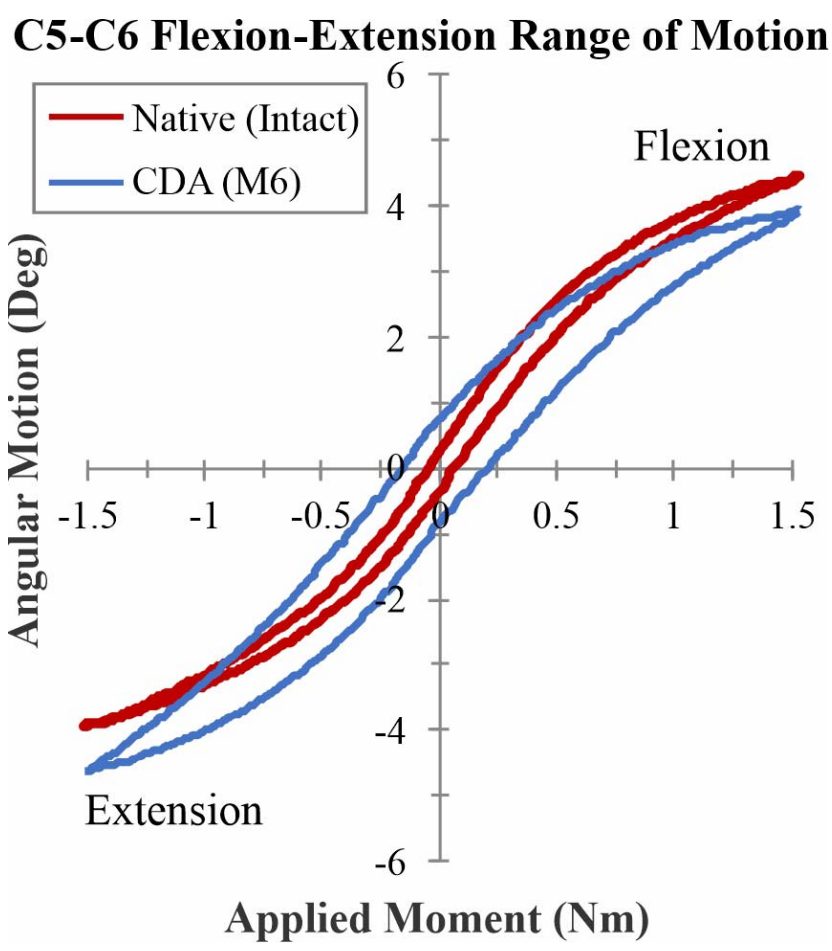

Figure 11. Examples of kinematic signatures of a cervical spine segment in flexion extension: intact (native) and after CDA using an M6-C disc prosthesis. CDA, cervical disc arthroplasty.

and the upper endplate. This may not be surprising because we made a similar observation in the Charité lumbar disc prosthesis, a mobile-core disc with 2 spherical bearings, where the flexion-extension motion at the implanted segment occurred preferentially at the upper bearing, dictated by the native anatomy of a lumbar segment whose COR is located just below the lower endplate of the intervertebral disc. ${ }^{55,56}$ However, the reasons for a similar observation in lateral bending remains unclear and further research is needed to better understand the response of a dual-bearing cervical disc prosthesis in lateral bending.

\section{Kinematic Signature}

The applied moment versus segmental angular motion curve (kinematic signature) of a segment after CDA is a combined result of the built-in bending stiffness of the disc prosthesis and the tensioning of the soft tissues such as the remaining disc annulus, posterior ligaments, and facet capsules. A few studies ${ }^{46,54,58-60}$ have reported the kinematic signature of cervical spine segments after CDA and compared the signature with that of healthy cervical spine segments (Figure 11).

It should be kept in mind that even though the disc prosthesis may lack built-in bending stiffness, the height of the prosthesis in relation to the native disc height and the location of the prosthesis COR can recruit the soft tissues to contribute enough stiffness to make the resulting kinematic signature resemble a healthy motion segment. However, this maybe at the cost of nonphysiologic strains induced in the ligaments and facet capsules ${ }^{41}$.

\section{PROSTHESIS DESIGN AND LOAD- SHARING IN THE 3-JOINT COMPLEX}

Cervical disc prostheses that do not allow independent translation, such as those with a single ball-and-socket joint or spherical bearing, will have a fixed COR in the sagittal and coronal planes over the full ROM of the segment. The prosthesis COR will be located at the center of the sphere and its location relative to the intervertebral disc will depend on the radius of curvature of the spherical bearing and its placement within the disc space. The axis of rotation for any motion will pass through the center of the sphere and will remain so over the full range of motion. If the bearing surfaces remain congruent throughout the arc of motion, the motion between the upper and lower prosthetic endplates will be dictated by the location of the COR. The natural COR of the cervical segment, on the other hand, is correlated with the location and orientation of the facet surfaces relative to the middisc plane. ${ }^{61}$ Therefore, in the presence of a mismatch between the locations of the prosthesis COR and the natural COR of a given cervical segment, the ligaments and facet capsules could experience abnormal strains and the facets may experience abnormal loads, upsetting the normal load-sharing characteristic of the cervical 3-joint complex. Another possible complication is that the bone-prosthesis interface may experience movement during flexion and extension motions of the segment to accommodate the mismatch in the COR locations.

Hypothetically, a disc prosthesis with a translational DOF, such as one provided by a 3component disc prosthesis with a mobile core or the 2-component prosthesis with a ball moving in a trough, has the potential to allow the prosthesis motion to be guided by the 3 -joint complex in response to the external loads acting on the spine. This will have the effect of the prosthesis working in concert with the functional spine unit anatomy, thereby reducing nonphysiological stresses and strains in the bony and soft tissue structures. However, the benefits of a 3-component prosthesis 

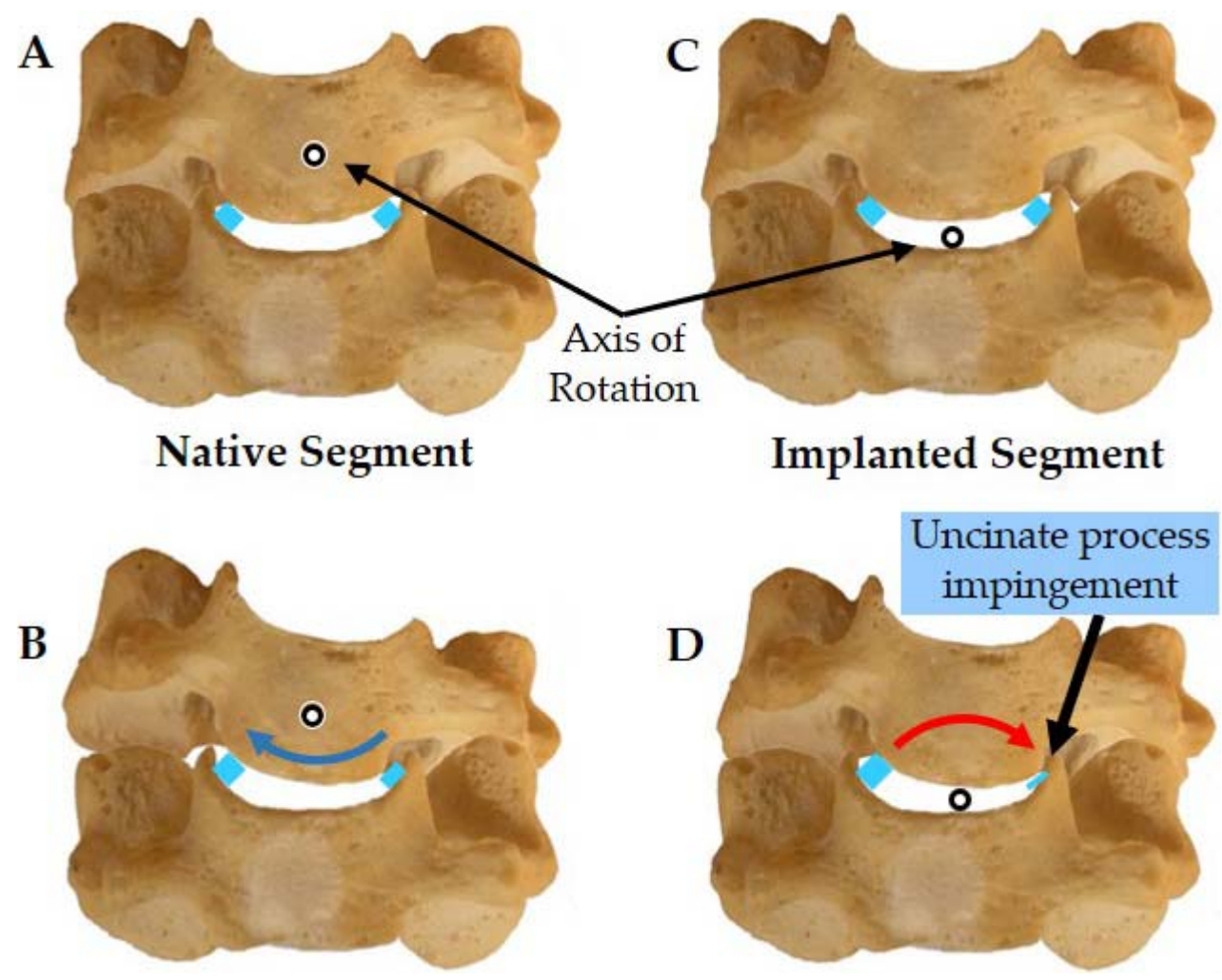

Figure 12. (A, B) Intact cervical segment with the physiologic lateral bending axis of rotation in the cranial body showing normal ROM in lateral bending. (C, D) Implanted cervical segment with nonphysiologic lateral bending axis of rotation in the disc space demonstrating uncinate impingement during lateral bending. ROM, range of motion.

rely on the mobile core being truly mobile during the arc of motion. The core can get trapped due to stiction or poor positioning at the time of implantation, which can lead to stick-slip motion of the core, whereby the core is trapped and immobile over a portion of the flexion-extension motion of the spine then suddenly released, resulting in highvelocity core motion and yielding a nonphysiologic kinematic signature characteristic of segmental instability. ${ }^{55,60}$

A mismatch between the lateral bending and axial rotation axes of the native segment and the prosthesis can cause abnormal facet contact and loading during these motions. Similarly, the uncinate processes may experience abutment because of abnormal motion coupling. This latter point is illustrated by taking an example of a singlespherical-bearing prosthesis (Figure 12).

During lateral bending the cranial vertebra of the native segment undergoes a "swinging" motion within the bowl formed by the superior endplate and uncinate processes of the inferior vertebra (Figure 12A, B). In contrast, the spherical bearingimplanted segment rotates about a more caudal axis of rotation, which is likely to result in abutment against the ipsilateral uncinate and increased tensile resistance of the soft tissue tether with the contralateral uncinate (Figure 12C, D). Such abnormal loading patterns in the facet joints and uncovertebral joints may lead to pain and further degeneration.

The design of a disc prosthesis can also influence the anatomic components that share the responsibility of resisting shear motions and loads. An implanted segment may experience large shear forces depending on the sagittal alignment of the cervical spine and the orientation of the implanted segment relative to the gravitational load vector of the head acting through the external auditory meatus. A ball-and-socket articulation in a 2component prosthesis bears the entire responsibility of resisting the shear forces that may act on the motion segment and transferring these shear stresses to the bone-prosthesis interface. On the other hand, a prosthesis that has an independent translational DOF and has no inherent or built-in resistance to shear will allow the mobile core to translate until either the built-in stops become active or the facets act as stops to block the anterior shear motion at the implanted segment. 


\section{INFLUENCE OF SURGICAL FACTORS ON FUNCTIONAL SPINE UNIT KINEMATICS AFTER CDA}

\section{Prosthesis Placement in the Disc Space}

Positioning the COR of the disc prosthesis slightly posterior to the midline of the intervertebral disc space allows better matching of the prosthesis COR to the COR of the intact segment. ${ }^{7,12}$ However, implantations in more anterior or more posterior positions are not uncommon in clinical practice. ${ }^{62,63}$ Many clinicians prefer to position the prosthesis so that it is supported by the strong posterior rim of the endplate, thereby reducing the incidence of subsidence. Depending on the design of the artificial disc prosthesis, the variability in positioning of the prosthesis in the disc space is likely to influence the ROM as well as the locations of axes of rotation, which in turn may influence the relative motions and contacts at facet and uncovertebral joints. ${ }^{57}$

\section{Integrity of the PLL}

The necessity for resection of the PLL during artificial disc replacement surgery for the cervical spine has been the subject of debate. Some advocate partial or complete resection of the PLL to allow thorough decompression, whereas others have stated the PLL may or may not be removed, depending on the location of herniation or osteophyte. $^{64}$ McAfee and colleagues ${ }^{28}$ found that the ROM in compression, flexion-extension, lateral bending, and axial rotation of an implanted segment with intact PLL was not significantly different from the range of motion during these modes with a PCM device in place and the PLL resected. Whereas the PLL resection significantly increased motion as compared with discectomy alone (without the PCM in the disc space), PLL resection did not affect the biomechanics of the reconstructed segment. In our laboratory experience, resection of the PLL facilitates more parallel disc space distraction and proper placement of the prosthesis. A disc prosthesis with inherent bending stiffness will more likely be able to restore stability to the implanted segment despite the resection of the PLL. ${ }^{65}$

\section{Prosthesis Disc Height}

Disc space distraction is a likely factor that can influence the kinematics of the cervical spine segment after disc arthroplasty. Overdistraction of the disc space is thought to decrease motion after CDA; however, there are few published biomechanical or clinical studies to quantify this effect. In a recent analysis of clinical data, Patwardhan et $\mathrm{al}^{66}$ showed that discs with a preoperative height less than $3 \mathrm{~mm}$ may be amenable to disc arthroplasty using compressible disc prostheses.

\section{Uncinate (Uncovertebral Joint) Resection}

Patients with moderate foraminal stenosis but who are still candidates for CDA may benefit from decompression involving partial uncinate process resection. This notion in combination with the previous discussion showing uncinate process abutment in lateral bending may appear to provide justification to prophylactically resect these lateral stabilizers. However, evidence in the literature shows that even unilateral uncinate resection can cause significant increase in flexion-extension motion, and further resection of the contralateral side may make the motion segment unstable. ${ }^{53}$ Clinical studies can provide further guidance linking the amount of direct uncinate resection, regrowth of osteophytes, and residual motion at the implanted segment.

\section{CONCLUSIONS}

The benefits of disc arthroplasty over fusion are based on the premise that preservation of physiologic motions and load-sharing at the treated level would lead to longevity of the index-level facet joints and mitigate the risk of adjacent segment degeneration. Recent studies have begun to provide long-term clinical data to support this premise. The ability of an artificial disc prosthesis to work in concert with the remaining bony and soft tissue structures to restore physiologic ROM and loadsharing is a function of the prosthesis design features as well as surgical factors:

1. Kinematic DOF-Prostheses that allow translation independent of rotation, in theory allow the spinal anatomy to dictate the segmental motion post-disc arthroplasty and are more likely to restore the physiologic ROM and load-sharing function. A 6-DOF disc prosthesis, therefore, is the most equipped to achieve the intended function of CDA. 
2. Built-in stiffness-A disc prosthesis with built-in resistance to angular and translational motion may have an advantage in restoring stability to a hypermobile segment without eliminating motion.

3. In addition to the prosthesis design features, several surgical factors related to implantation of the prosthesis may influence the response of cervical segments after disc arthroplasty. These factors include the amount of disc space distraction caused by the prosthesis height relative to the initial disc height; prosthesis placement in the sagittal and coronal planes; and integrity of the soft tissue envelope, which could be a balancing act between maintaining postoperative stability and releasing enough tissue to implant the prosthesis in what is considered optimal positioning for a given prosthesis design.

Meaningful differences between disc prostheses come down to the allowed DOF, location of the axis of rotation for a given motion, and device stiffness. How these device characteristics allow the prosthesis to work with the patient's anatomy will, in the end, determine whether the prosthesis is successful at restoring motion and mitigating adjacent-level stresses. Biomechanics has a strong role in defining these differences, but clinical data are ultimately needed to understand how individual prostheses function within a diseased or degenerative spine.

\section{REFERENCES}

1. Mimura M, Moriya H, Watanabe T, Takahashi K, Yamagata M, Tamaki T. Three-dimensional motion analysis of the cervical spine with special reference to the axial rotation. Spine (Phila Pa 1976). 1989;14:1135-1139.

2. Holmes A, Wang C, Han ZH, Dang GT. The range and nature of flexion-extension motion in the cervical spine. Spine (Phila Pa 1976). 1994;19:2505-2510.

3. Ishii T, Mukai Y, Hosono N, et al. Kinematics of the cervical spine in lateral bending: in vivo three-dimensional analysis. Spine (Phila Pa 1976). 2006;31:155-160. doi:00007632-200601150-00007

4. Goel VK, Clark CR, McGowan D, Goyal S. An in-vitro study of the kinematics of the normal, injured and stabilized cervical spine. $J$ Biomech. 1984;17:363-376. doi:00219290(84)90030-7

5. Panjabi MM, Summers DJ, Pelker RR, Videman T, Friedlaender GE, Southwick WO. Three-dimensional loaddisplacement curves due to forces on the cervical spine. $J$ Orthop Res. 1986;4:152-161. doi:10.1002/jor.1100040203

6. Moroney SP, Schultz AB, Miller JA, Andersson GB.
Load-displacement properties of lower cervical spine motion segments. J Biomech. 1988;21:769-779.

7. Bogduk N, Mercer S. Biomechanics of the cervical spine. I: Normal kinematics. Clin Biomech (Bristol, Avon). 2000;15:633-648. doi:S0268-0033(00)00034-6

8. Panjabi MM, Crisco JJ, Vasavada A, et al. Mechanical properties of the human cervical spine as shown by threedimensional load-displacement curves. Spine (Phila Pa 1976). 2001;26:2692-2700.

9. Ferrario VF, Sforza C, Serrao G, Grassi G, Mossi E. Active range of motion of the head and cervical spine: a threedimensional investigation in healthy young adults. $J$ Orthop Res. 2002;20:122-129. doi:10.1016/S0736-0266(01)00079-1

10. Senouci M, FitzPatrick D, Quinlan JF, Mullett H, Coffey L, McCormack D. Quantification of the coupled motion that occurs with axial rotation and lateral bending of the head-neck complex: an experimental examination. Proc Inst Mech Eng H. 2007;221:913-919.

11. Yoganandan N, Pintar FA, Stemper BD, Wolfla CE, Shender BS, Paskoff G. Level-dependent coronal and axial moment-rotation corridors of degeneration-free cervical spines in lateral flexion. J Bone Joint Surg Am. 2007;89:1066-1074. doi: 10.2106/JBJS.F.00200

12. Hipp JA, Wharton ND. Quantitative motion analysis (QMA) of motion-preserving and fusion technologies for the spine. In: Yue JJ, Bertagnoli R, McAfee PC, An HS, eds. Motion Preservation Surgery of the Spine. Philadelphia, PA: Saunders Elsevier; 2008:85-96.

13. Robinson R, Smith G. Anterolateral cervical disc removal and interbody fusion for cervical disc syndrome. Bull John Hopkins Hosp. 1955;96:223-224.

14. Bailey R, Badgely C. Stabilization of the cervical spine by anterior fusion. J Bone Joint Surg Am. 1960;42:565-594.

15. Gore D, Sepic S. Anterior cervical fusion for degenerated or protruded discs: a review of one hundred forty-six patients. Spine. 1984;9:667-671.

16. Bohlman H, Emery S, Goodfellow D, et al. Robinson anterior cervical discectomy and arthrodesis for cervical radiculopathy: long term follow-up of one hundred and twenty-two patients. J Bone Joint Surg Am. 1993;75:12981307.

17. Baba H, Furusawa N, Imura S, Kawahara N, Tsuchiya $\mathrm{H}$, Tomita $\mathrm{K}$. Late radiographic findings after anterior cervical fusion for spondylotic myeloradiculopathy. Spine (Phila Pa 1976). 1993;18:2167-2173.

18. Hilibrand AS, Carlson GD, Palumbo MA, Jones PK, Bohlman HH. Radiculopathy and myelopathy at segments adjacent to the site of a previous anterior cervical arthrodesis. J Bone Joint Surg Am. 1999;81:519-528.

19. Wigfield C, Gill S, Nelson R, Langdon I, Metcalf N, Robertson J. Influence of an artificial cervical joint compared with fusion on adjacent-level motion in the treatment of degenerative cervical disc disease. J Neurosurg. 2002;96:17-21.

20. Goffin J, Geusens E, Vantomme N, et al. Long-term follow-up after interbody fusion of the cervical spine. $J$ Spinal Disord Tech. 2004;17:79-85.

21. Ishihara $H$, Kanamori M, Kawaguchi $Y$, Nakamura $H$, Kimura T. Adjacent segment disease after anterior cervical 
interbody fusion. Spine J. 2004;4:624-628. doi:S15299430(04)00229-3

22. Fuller DA, Kirkpatrick JS, Emery SE, Wilber RG, Davy DT. A kinematic study of the cervical spine before and after segmental arthrodesis. Spine (Phila Pa 1976). 1998;23:1649-1656.

23. Eck J, Humphreys S, Lim T, et al. Biomechanical study on the effect of cervical spine fusion on adjacent level intradiscal pressure and segment motion. Spine. 2002;27:2431-2434.

24. DiAngelo DJ, Roberston JT, Metcalf NH, McVay BJ, Davis RC. Biomechanical testing of an artificial cervical joint and an anterior cervical plate. J Spinal Disord Tech. 2003; 16:314-323.

25. Dmitriev AE, Cunningham BW, Hu N, Sell G, Vigna F, McAfee PC. Adjacent level intradiscal pressure and segmental kinematics following a cervical total disc arthroplasty: an in vitro human cadaveric model. Spine (Phila Pa 1976). 2005;30:1165-1172. doi:00007632-200505150-00011

26. Patwardhan AG, Khayatzadeh S, Nguyen NL, et al. Is cervical sagittal imbalance a risk factor for adjacent segment pathomechanics after multilevel fusion? Spine (Phila $\mathrm{Pa}$ 1976). 2016;41(10):E580-E588.

27. Bryan VE Jr. Cervical motion segment replacement. Eur Spine J. 2002;11(suppl 2):S92-S97. doi:10.1007/s00586002-0437-3

28. McAfee PC, Cunningham B, Dmitriev A, et al. Cervical disc replacement-porous coated motion prosthesis: a comparative biomechanical analysis showing the key role of the posterior longitudinal ligament. Spine (Phila Pa 1976). 2003;28:S176-S185. doi:10.1097/01.BRS.0000092219.28382. $0 \mathrm{C}$

29. Duggal N, Pickett GE, Mitsis DK, Keller JL. Early clinical and biomechanical results following cervical arthroplasty. Neurosurg Focus. 2004;17:E9. doi: 10.3171/foc.2004. 17.3.9

30. Le H, Thongtrangan I, Kim DH. Historical review of cervical arthroplasty. Neurosurg Focus. 2004;17:E1. doi: 10. 3171/foc.2004.17.3.1

31. Pimenta L, McAfee PC, Cappuccino A, Bellera FP, Link HD. Clinical experience with the new artificial cervical PCM (Cervitech) disc. Spine J. 2004;4:315S-321S. doi:S15299430(04)00591-1

32. Traynelis VC. Cervical arthroplasty. Clin Neurosurg. 2006;53:203-207.

33. Sasso RC, Smucker JD, Hacker RJ, Heller JG. Artificial disc versus fusion: a prospective, randomized study with 2-year follow-up on 99 patients. Spine. 2007;32(26):29332940.

34. Jaramillo-de la Torre JJ, Grauer JN, Yue JJ. Update on cervical disc arthroplasty: where are we and where are we going? Curr Rev Musculoskelet Med. 2008;1:124-130. doi:10. 1007/s12178-008-9019-2

35. Sasso R, Anderson P, Riew K, et al. Results of cervical arthroplasty compared with anterior discectomy and fusion: four-year clinical outcomes in a prospective, randomized, controlled trial. J Bone Joint Surg Am. 2011;93:1684-1692.

36. Coric D, Nunley PD, Guyer RD, et al. Prospective, randomized, multicenter study of cervical arthroplasty: 269 patients from the Kineflex $\mathrm{C}$ artificial disc investigational device exemption study with a minimum 2-year follow-up. $J$ Neurosurg Spine. 2011;15(4), 348-358.

37. Zigler JE, Delamarter R, Murrey D, Spivak J, Janssen M. ProDisc-C and anterior cervical discectomy and fusion as surgical treatment for single-level cervical symptomatic degenerative disc disease: five-year results of a Food and Drug Administration study. Spine. 2013;38(3):203-209.

38. Davis RJ, Kim KD, Hisey MS, et al. Cervical total disc replacement with the Mobi-C cervical artificial disc compared with anterior discectomy and fusion for treatment of 2-level symptomatic degenerative disc disease: a prospective, randomized, controlled multicenter clinical trial. J Neurosurg Spine. 2013:19(5):532-545.

39. Gornet MF, Burkus JK, Shaffrey ME, Argires PJ, Nian H, Harrell FE. Cervical disc arthroplasty with PRESTIGE LP disc versus anterior cervical discectomy and fusion: a prospective, multicenter investigational device exemption study. J Neurosurg Spine. 2015;23(5):558-573.

40. Hisey MS, Zigler JE, Jackson R, et al. Prospective, randomized comparison of one-level Mobi-C cervical total disc replacement vs. anterior cervical discectomy and fusion: results at 5-year follow-up. Int J Spine Surg. 2016;10:1-10. doi: $10.14444 / 3010$

41. Sears W, McCombe P, Sasso R. Kinematics of cervical and lumbar total disc replacement. Semin Spine Surg. 2006;18:117-129.

42. Büttner-Janz K. Classification of spine arthroplasty devices. In: Yu JJ, Bertagnoli R, McAfee PC, An HS, eds. Motion Preservation Surgery of the Spine. Philadelphia, Pa: Saunders Elsevier Press; 2008:21-35.

43. Huang RC, Girardi FP, Cammisa FP, Wright TM. (2003). The implications of constraint in lumbar total disc replacement. Spine. 2003;28:412-417.

44. Soni AH. Mechanism Synthesis and Analysis. New York, NY: McGraw-Hill; 1974.

45. Finn MA, Brodke DS, Daubs M, Patel A, Bachus KN. Local and global subaxial cervical spine biomechanics after single-level fusion or cervical arthroplasty. Eur Spine J. 2009;18:1520-1527. doi:10.1007/s00586-009-1085-7

46. Havey RM, Khayatzadeh S, Voronov LI, et al. Motion response of a polycrystalline diamond adaptive axis of rotation cervical total disc arthroplasty. Clin Biomech. 2019;62:34-41.

47. Patwardhan AG, Havey RM, Carandang G, et al. Effect of compressive follower preload on the flexionextension response of the human lumbar spine. J Orthop Res. 2003;21:540-546. doi:S0736026602002024

48. Richter M, Wilke HJ, Kluger P, Claes L, Puhl W. Load-displacement properties of the normal and injured lower cervical spine in vitro. Eur Spine J. 2000;9(2):104-108.

49. Panjabi MM. The stabilizing system of the spine. Part II. Neutral zone and instability hypothesis. J Spinal Disord. 1992;5:390-396, discussion 397.

50. Patwardhan AG, Voronov L, Havey RM, et al. P152. Limited restoration of primary and coupled motions in lateral bending and axial rotation after total disc replacement: a common finding in cervical disc prostheses [abstract]. Spine J. 2009;9(10):S192-S193. 
51. Puttlitz CM, Rousseau MA, Xu Z, Hu S, Tay BK, Lotz JC. Intervertebral disc replacement maintains cervical spine kinetics. Spine (Phila Pa 1976). 2004;29:2809-2814. doi:00007632-200412150-00005

52. Puttlitz CM, DiAngelo DJ. Cervical spine arthroplasty biomechanics. Neurosurg Clin N Am. 2005;16:589-594, v. doi:S1042-3680(05)00052-5

53. Snyder JT, Tzermiadianos MN, Ghanayem AJ, et al. Effect of uncovertebral joint excision on the motion response of the cervical spine after total disc replacement. Spine (Phila Pa 1976). 2007;32:2965-2969. doi: 10.1097/BRS. $0 \mathrm{~b} 013 \mathrm{e} 31815 \mathrm{~cd} 482$

54. Guyer RD, Voronov LI, Havey RM, et al. Kinematic assessment of an elastic-core cervical disc prosthesis in one and two-level constructs. JOR Spine. 2018;1(4):e1040.

55. O'Leary P, Nicolakis M, Lorenz MA, et al. Response of Charité total disc replacement under physiologic loads: prosthesis component motion patterns. Spine $J$. 2005;5(6):590-599.

56. Patwardhan AG, Havey RM, Wharton ND, et al. (2012). Asymmetric motion distribution between components of a mobile-core lumbar disc prosthesis: an explanation of unequal wear distribution in explanted CHARITÉ polyethylene cores. J Bone Joint Surg Am. 2012;94(9):846-854.

57. Patwardhan AG, Tzermiadianos MN, Tsitsopoulos PP, et al. Primary and coupled motions after cervical total disc replacement using a compressible six-degree-of-freedom prosthesis. Eur Spine J. 2012;21(5):618-629.

58. Martin S, Ghanayem AJ, Tzermiadianos MN, et al. Kinematics of cervical total disc replacement adjacent to a two-level, straight versus lordotic fusion. Spine. 2011;36(17):1359-1366.

59. Lee MJ, Dumonski M, Phillips FM, et al. Disc replacement adjacent to cervical fusion: a biomechanical comparison of hybrid construct versus two-level fusion. Spine. 2011;36(23):1932-1939.

60. Patwardhan AG, Havey RM. Prosthesis design influences segmental contribution to total cervical motion after cervical disc arthroplasty. Eur Spine J. 2019:Jul 15:1-9. doi: 10.1007/s00586-019-06064-4

61. Milne N. The role of zygapophysial joint orientation and uncinate processes in controlling motion in the cervical spine. J Anat. 1991;178:189.
62. Mehren C, Suchomel P, Grochulla F, et al. Heterotopic ossification in total cervical artificial disc replacement. Spine (Phila Pa 1976). 2006;31:2802-2806. doi:10.1097/01.brs. 0000245852.70594.d5

63. Sekhon LH, Duggal N, Lynch JJ, et al. Magnetic resonance imaging clarity of the Bryan, Prodisc-C, Prestige LP, and PCM cervical arthroplasty devices. Spine (Phila Pa 1976). 2007;32:673-680. doi:10.1097/01.brs.0000257547. 17822.14

64. Delamarter RB, Pradhan BB. ProDisc-C total cervical disc replacement. In: Yue JJ, Bertagnoli R, McAfee PC, An HS, eds. Motion Preservation Surgery of the Spine. Philadelphia, PA: Saunders Elsevier; 2008:214-220.

65. Voronov LI, Havey RM, Tsitsopoulos PP, et al. Does resection of the posterior longitudinal ligament affect the stability of cervical disc arthroplasty? Int J Spine Surg. 2018;12(2):285-294.

66. Patwardhan AG, Carandang G, Voronov LI, et al. Are collapsed cervical discs amenable to total disc arthroplasty? Analysis of prospective clinical data with 2-year follow up. Spine. 2016;41(24):1866-1875.

Disclosures and COI: Avinash Patwardhan is a consultant to Orthofix Medical Inc, Lewisville, TX, USA. Robert Havey has nothing to disclose. Institutional research funds were received from Stryker, DePuy Synthes, Orthofix Medical, Medtronic, and International Surgical SEZC.

Corresponding Author: Avinash G. Patwardhan, $\mathrm{PhD}$, Loyola University Medical Center, 2160 South First Ave, Maywood, IL 60153. Phone: (630) 430-7612; Email: apatwar@lumc.edu.

Published 30 September 2020

This manuscript is generously published free of charge by ISASS, the International Society for the Advancement of Spine Surgery. Copyright @ 2020 ISASS. To see more or order reprints or permissions, see http://ijssurgery.com. 